\title{
Sex-related in vitro/in vivo and PK/PD correlations after oral single dose furosemide administration
}

\author{
Laura Magallanes ${ }^{1}$, Pietro Fagiolino ${ }^{1 *}$, Marta Vazquez ${ }^{1}$, Nikoletta Fotaki², Manuel Ibarra ${ }^{1}$, Marianela Lorier ${ }^{1}$, Virginia Bertola ${ }^{3}$ and \\ Anna Barindelli ${ }^{3}$
}

*Correspondence: pfagioli@fq.edu.uy

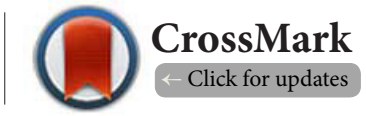

\begin{abstract}
'Department of Pharmaceutical Sciences, Faculty of Chemistry, Bioavailability and Bioequivalence Center for Medicine Evaluation, University of the Republic, Uruguay.

${ }^{2}$ Department of Pharmacy and Pharmacology, University of Bath, Bath, United Kingdom.

${ }^{3}$ Department of Clinical Laboratory, Faculty of Medicine, University of the Republic, Uruguay.
\end{abstract}

\begin{abstract}
Background: The goal of this study was to develop an in vivo-in vitro (IVIV) correlation, both in men and women, which allows constructing a model to predict bioequivalence assessments for drugs with narrow absorption windows. Besides, pharmacokinetic and pharmacodynamic equivalences were also investigated. Furosemide was chosen as a prototype.

Methods: Twelve healthy Caucasian volunteers (8 women and 4 men) participated in a relative bioavailability study. Two oral formulations [Lasix ${ }^{\circledR}$ (Reference, R) and Furosemide EFA $^{\circledR}($ Test, T) $]$ were administered under fasting conditions. Urinary excretion of unchanged drug (PK), and of chloride, sodium and potassium (PD) wasmonitored throughout time. PK and PD parameters were calculated from each respective excretion rate versus time curve. In vitro dissolution testing of both formulations was carried out using the USP apparatus 2 and 4 with fixed and variable dissolution media.

Results: $\mathrm{T}$ and $\mathrm{R}$ could be considered bioequivalent since the $90 \%$ confidence intervals for the $\mathrm{T} / \mathrm{R}$ ratio of geometric means for the area under the urinary drug excretion rate versus time curve and for the maximum excretion rate were within the 0.80-1.25 bioequivalence interval. However, T had faster initial absorption and higher levels in women, while $\mathrm{R}$ displayed such characteristics in men. Closer IVIV correlations in women were obtained when apparatus 4 with variable biorelevant dissolution media were used [going from fasting state simulated gastric fluid to fasting state simulated intestinal fluid]. Since $\mathrm{R}$ had faster disintegration time than $\mathrm{T}$, a shorter stay of $\mathrm{R}$ under gastric conditions was required in order to obtain a good IVIV correlation in men. Saluretic effect displayed a typical clockwise hysteresis loop for the PKPD correlation assessed through chloride-versus-furosemide urinary excretion rates. Even though a higher amount of furosemide was excreted with the urine in men, differences in the excretion of electrolytes between sexes were almost negligible.

Conclusions: Sex-differences in the gastrointestinal transit of formulations, under fasting conditions, determined the extent and the rate of furosemide absorption. The prolongation of the absorption process by mean of slowing the gastric emptying would make the formulation more effective. The USP-4 apparatus with variable dissolution media was able to discriminate the formulations even between sexes, becoming a promissory in vitro dissolution testing to predict bioequivalence.
\end{abstract}

Keywords: Furosemide, oral absorption, IVIV and PKPD correlations, sex-by-formulation interaction, bioequivalence

\section{Introduction}

Furosemide is a loop diuretic that is commonly used in the treatment of edematous states associated with cardiac, renal, hepatic failure and in the treatment of uncontrolled hypertension with abnor- 
Magallanes et al. Journal of Pharmaceutical Technology \& Drug Research 2016,

http://www.hoajonline.com/journals/pdf/2050-120X-5-2.pdf

doi: 10.7243/2050-120X-5-2

mal renal function. Its oral bioavailability is low (67\%) even if a solution of $40 \mathrm{mg}$ is given to healthy male subjects [1]. In a study carried out with women and men [2], absolute bioavailability under fasting state was reduced to $51 \%$ revealing a sex-related influence on the oral absorption of furosemide. Sustained-release formulations rendered even lower drug absorption [3,4]. Switching from intravenous bolus to oral slow release dosage forms, more than three quarters of the administered dose were not absorbed. Therefore, drug dissolution might play a significant role in furosemide absorption as it was previously reported $[\mathbf{5 , 6 ]}$. Further extensive information about furosemide oral absorption and an appropriate background for this work can be found in Magallanes et al., 2015 [7].

\section{Materials and methods Equipment}

GFL 2008 distillation apparatus (Germany) to provide distilled water, andOakton ph6 pH-meter (IL, United States) to adjust the $\mathrm{pH}$ of dissolution media were used.

To perform in vitro dissolution testing the following equipment was used. USP apparatus 2 (paddle method): Distek ${ }^{\otimes}$ dissolution system $2100 \mathrm{C}$ equipment, configured with a model $89092 \mathrm{EO}$ Agilent peristaltic pump, and coupled with spectrophotometer Agilent 8453. A software ChemStation ${ }^{\circledR}$ CPU (Agilent) controlled all the dissolution testing. USP apparatus 4: a Sotax CE 7 smart USP-4 flow through dissolution system connected to a Sotax CP-7 35 Piston Pump (Sotax, Switzerland), and collected samples assayed by a spectrophotometer UV-Vis Thermo Spectronic, (model HeliosGamma, Thermo Scientific, UK).

When dissolution was under biorelevant condition the collected samples were assayed by HPLC system, consisting of an Agilent 1200 series binary pump (G1312A), an Agilent 1200 series DAD detector (G1315D), an Agilent 1200 series autosampler (G1329A), an Agilent 1200 series controller (G1316A) and a Chemstation software (Agilent Technologies, Santa Clara, United States). The column was Thermo Hypersil BDS C18, 300Å, 250x4.6 mm, $5 \mu \mathrm{m}$.

In vitro disintegration times of formulations were measured with the USP disintegration apparatus (U.S. Pharmacopeial Convention, 2014) provided by local vendor (Tecnolab ${ }^{\circledR}$, without disks. Individual disintegration times were manually recorded once dosage forms were completely broken down.

Furosemide urine concentrations were measured by high performance liquid chromatography coupled with ultraviolet detector (HPLC-UV) with Dionex ${ }^{\circledast}$ Ultimate 3000 system equipped with a Phenomenex ${ }^{\otimes}$ Luna $\mathrm{C} 18$ reverse phase column $(5 \mu \mathrm{m}, 150 \times 4.6 \mathrm{~mm})$ kept at $40^{\circ} \mathrm{C}$.

Electrolytes (chloride, sodium, and potassium) in urine were measured with Cobas c311 analyzer (Cobas ${ }^{\circledR} 4000$ analyzer series, Roche/Hitachi).

\section{Chemicals}

Assayed formulations were two brands marketed in Uruguay as immediate-release tablets containing $40 \mathrm{mg}$ of furosemide: Furosemide EFA (Antia Moll, batch 028, expiration date Jan/2019, Test formulation [T]), and Lasix ${ }^{\circledast}$ (Sanofi Aventis, batch 1D034M, expiration date May/2017, Reference formulation[R]). Furosemide powder used as standard was obtained from Antia Moll Laboratory.

Hydrochloric acid from Dorwil(Argentine) and potassium chloride from Carlo Erba(Milano, Italy) were used to prepare the simulated gastric ( $\mathrm{pH}$ 2.2) fluid. Acetate buffer $\mathrm{pH} 4.6$ was prepared with glacial acetic acid and sodium acetate (Sigma-Aldrich [Dorset, England]) accordingly with USP-30. Fasted State Simulated Gastric Fluid (FaSSGF) and Fasted State Simulated Intestinal Fluid version 2 (FaSSIF-V2), whose compositions are informed elsewhere (Fotaki and Vertzoni, 2010), were prepared with the following ingredients:hydrochloric acid 36.5-38\%, and pepsin (from porcine) from Sigma-Aldrich (Dorset, England); maleic acid, sodium chloride, and sodium hydroxide from Fisher Scientific UK Ltd. (Loughborough, England), sodium taurocholate from Prodotti Chimici Alimentari S.P.A.(Basaluzzo, Italy); and egg lecithin - Lipoid EPCS from Lipoid GmbH(Ludwigshafen, Germany). Formic acid (from Sigma-Aldrich [Dorset, England]) and methanol HPLC-grade (from Merck (Darmstadt, Germany) were used for the preparation ofthe mobile phase for furosemide quantification in the samples from the in vitro biorelevant dissolution studies.

The organic solvents used for extraction of furosemide from the urine of volunteers ( $\mathrm{n}$-hexane [from Merck (Darmstadt, Germany)] and ethyl acetate [from Dorwil (Argentine)]) and for preparing standard solutions (methanol [from Pharmaco \& Aaper (USA)]) were of analytical grade. Buffer prepared with potassium dihydrogen phosphate and phosphoric acid from Labsynth (Sao Paulo, Brazil), in adjunction with acetonitrile HPLC-grade (from Merck [Darmstadt, Germany]) was used as mobile phase for drug quantification in urine. The internal standard, phenytoin, was obtained from Fármaco Uruguayo Laboratory (Uruguayan pharmaceutical company).

\section{In vitro disintegration at $\mathrm{pH} 2.5$}

Six units of each product were tested for disintegration according to the United States Pharmacopoeia (USP30-NF35, physicochemical methods $<701>$ ) using the simulated gastric fluid without enzyme (aqueous solution of $\mathrm{HCl}$ and $\mathrm{KCl}, \mathrm{pH} 2.5$ ).

\section{In vitro dissolution with USP-2 apparatus ( $\mathrm{pH} 4.6)$}

Dissolution of six units of each formulation was performed in medium acetate buffer $\mathrm{pH} 4.6$, at $37 \pm 0.5^{\circ} \mathrm{C}$, volume $900 \mathrm{~mL}$; stirring speed $50 \mathrm{rpm}$, sampling times: 5, 10, 15, 20, 30, 40, 60 , and $90 \mathrm{~min}$. Quantification of furosemide concentrations in the dissolution samples was carried out by UV-absorption at $277 \mathrm{~nm}$ wavelength based on calibration curves in the dissolution medium.

In vitro dissolution with USP-4 apparatus

Dissolution studies of the $T$ and $\mathrm{R}$ formulations were performed 
with the flow through system operating in the open mode at $37 \pm 0.5^{\circ} \mathrm{C}$. A $5 \mathrm{~mm}$-size glass bead was positioned in the tip of the $\varnothing 22.6 \mathrm{~mm}$ cell, the cone was filled with $1 \mathrm{~mm}$-size glass beads and on the top of the cell a Whatman ${ }^{\circledR}$ glass fiber filter (GF/F: $0.7 \mu \mathrm{m}$ pore size) was placed. Formulations were placed on the tablet holder.

\section{Dissolution at pH 4.6}

The assay was carried out in medium pH 4.6 acetate buffer at $37 \pm 0.5^{\circ} \mathrm{C}$. Flow rate was set at $16 \mathrm{~mL} / \mathrm{min}$ in order to allow the formulation to be in contact through 60 minutes with approximately the same volume of solvent as in the USP-2 assay ( $960 \mathrm{~mL}$ vs $900 \mathrm{~mL}$ ). Samples were collected every 15 minutes and quantified as it was indicated under the dissolution with USP-2 $\mathrm{pH} 4.6$ section.

\section{Dissolution in variable biorelevant media from-1.6-to-6.5 pHs} Dissolution of furosemide from the formulations was monitored in triplicate using biorelevant media in order to simulate the in vivo dissolution of both formulations under fasted state $[\mathbf{8}, \mathbf{9}]$. Sequential change of both the dissolution medium and the flow rate was performed: from FaSSGF pH 1.6 at $8 \mathrm{~mL} / \mathrm{min}$ for $60 \mathrm{~min}$ to FaSSIF-V2 pH 6.5 at $4 \mathrm{~mL} / \mathrm{min}$ for $90 \mathrm{~min}$. Samples were collected every 15 minutes. Furosemide concentration in the dissolution sample was quantified by an HPLC method adapted from Sora et al., 2010 [10], using methanol:formic acid $0.1 \%(\mathrm{v} / \mathrm{v}) 60: 40$ as mobile phase, $0.8 \mathrm{~mL} / \mathrm{min}$ as flow rate, $25^{\circ} \mathrm{C}$ as run temperature, $20 \mu \mathrm{L}$ as injection volume, and $233 \mathrm{~nm}$ as detection wavelength.

\section{Subjects and in vivo study design}

Twelve Caucasian healthy volunteers (eight women and four men) between 21 and 37 years old with mean body weight (SD) of 64 (5) and 77 (21) kg, respectively, were enrolled. The study was carried out with one tablet $(40 \mathrm{mg}$ ) of the formulation T, or the formulation $\mathrm{R}$, administered under fasting conditions with $200 \mathrm{~mL}$ of water, in a randomized, two-period, two-sequence (TR and RT), balanced crossover design. A one-week washout period was kept between both administrations. The study protocol and informed consent form were designed according to the ethical guidelines for human clinical research and were approved by the Institutional Ethics Review Committee of the Faculty of Chemistry (Uruguay). Written informed consent was obtained from all subjects before their entry in the study. The study was performed in the Bioavailability and Bioequivalence Centre for Medicine Evaluation, situated in "Dr. Juan J. Crottogini" Hospital (Montevideo, Uruguay).

Volunteers came to the Centre the first day of each week with an eight-hour overnight fasting period. Urine samples were collected before dosing and at 20,40,60, 80, 100, 120, $140,160,180,240,300,360,420,480,600$, and 720 min after dosing. The volume of urine was registered and two aliquots, one for electrolytes determination (chloride, sodium, potassium) and the other for furosemide quantification, were stored until analysis, refrigerated $\left(2-8^{\circ} \mathrm{C}\right)$ and frozen $\left(-20^{\circ} \mathrm{C}\right)$ respectively. Standardized meals (lunch, tea, and dinner) were provided at 5, 8, and $12 \mathrm{~h}$ after dose administration. From 40 to $180 \mathrm{~min}$ post-dose, and following each urine sampling, $70 \mathrm{~mL}$ of rehydration fluid, prepared after water dilution of Rehidron ${ }^{\oplus}$, was given to the subjects. From $3 \mathrm{~h}$ post-dose, volunteers were rehydrated with $100 \mathrm{~mL}$ of fluid every hour after each urine sample collection. The fluid contained 15 $\mathrm{mmol} / \mathrm{L}$ sodium, $4 \mathrm{mmol} / \mathrm{L}$ potassium, $13 \mathrm{mmol} / \mathrm{L}$ chloride, $15 \mathrm{mmol} / \mathrm{L}$ glucose, $2 \mathrm{mmol} / \mathrm{L}$ citrate.

\section{Chemical analysis in urine}

Quantification of furosemide in urine was carried out by HPLC, based on the method described by Abou-Auda et al., 1998 [11] with minor modifications. Briefly, the assay was a liquid-liquid extraction of furosemide (with $n$-hexane : ethyl acetate [50:50]) from the urinary matrix $(250 \mu \mathrm{L})$ by the addition of $250 \mu \mathrm{L}$ of phosphoric acid $2.5 \mathrm{M}$ and $50 \mu \mathrm{L}$ of a methanolic solution of internal standard (phenytoin, $40 \mu \mathrm{g} / \mathrm{mL}$ ). Ten seconds of gentle agitation by vortex, separation of the organic phase, and evaporation until dryness under stream of nitrogen. Reconstitution of the residue was performed with mobile phase (buffer phosphate $0.02 \mathrm{M} \mathrm{pH} 3.5$ : acetonitrile [65:35]). A volume of $20 \mu \mathrm{L}$ was injected onto the reversed-phase column and eluates were monitored at $230 \mathrm{~nm}$. Retention times of analytes were: $5.5 \mathrm{~min}$ (furosemide) and $7.7 \mathrm{~min}$ (phenytoin). Linearity was assessed between 0.5 to $20 \mu \mathrm{g} / \mathrm{mL}$ of furosemide in urine. The lower limit of quantification was $0.5 \mu \mathrm{g} / \mathrm{mL}$, since intra-and-inter-day precision was below $20 \%$, in terms of coefficient of variation, and accuracy. Otherwise, precision and accuracy was comprised between $\pm 15 \%$ and within the $85-115 \%$ interval, respectively.

Chloride, sodium, and potassium electrolytes were measured accordingly with the instructions given by the manufacturers (Roche/Hitachi, package insert).

\section{Pharmacokinetic (furosemide) and pharmacodynamic (electrolytes) analysis}

The volume of urine was multiplied by furosemide and ions concentrations in urinary samples in order to obtain the amount of analyte $(\Delta A)$ in each interval of time $(\Delta T)$. By summing all $\Delta \mathrm{A}$, the total amount excreted in the urine of each analyte was obtained for the 12-hour study period $\left(\mathrm{E}_{0-12}\right)$. Urinary excretion rates for each analyte (ER) were calculated dividing $\Delta A$ by $\Delta T$ and the result was assigned to the middle of the $\Delta T$ interval. Urinary excretion rates of electrolytes were recorded as the pharmacodynamic responses (PDs) of the formulation given, and urinary excretion rate of furosemide as the corresponding pharmacokinetic response (PK). Non-compartmental PK/PD analysis for each analyte was performed over each ER versus time curve (Microsoft Office Excel 2007 software). The maximum ER $\left(E R_{\text {MAX }}\right)$ and the time-to-peak $\left(T_{M A X}\right)$ were recorded from experimental data for each volunteer and analyte. The area under the ER-time curve from zero to infinite $\left(A \cup C_{\mathbb{I N F}}\right)$, 
for furosemide, was calculated using the trapezoidal rule until the last experimental time ( $A \cup C_{11 \text {-hour }}$, and extrapolated to infinite adding the term $\mathrm{ER}_{11} / \mathrm{k}_{\mathrm{EL}}$, being $\mathrm{k}_{\mathrm{EL}}$ the first order elimination rate constant calculated from the slope of the terminal log-linear ER-time regression of data. $A U C_{I N F}$ corresponds to the total amount of furosemide excreted in urine $\left(\mathrm{E}_{\mathrm{INF})}\right.$. Furosemide half-life $\left(\mathrm{T}_{1 / 2}\right)$ was calculated as $\operatorname{Ln}(2) / \mathrm{k}_{\mathrm{EL}}$.

\section{Statistical analysis}

ER versus time curves for both electrolytes and furosemide aregraphed as mean values \pm standard error (SE). However, electrolyte versus furosemide ERs are presented as mean values \pm standard error of the electrolyte only, since it is set to assess if the same pharmacokinetic response could be associated with different pharmacodynamic response. If there was a significant difference $(p<0.05)$ between two excretion rates of the electrolyte, then a significant hysteresis for the PK/PD relationship was assessed.

Pharmacokinetic parameters for furosemide $\left(\mathrm{ER}_{\mathrm{MAX}} \mathrm{E}_{0-12^{\prime}}\right.$ and $\left.\mathrm{E}_{\mathrm{INF}}\right)$, in logarithmic scale, were processed by analysis of variance (ANOVA, Microsoft Office Excel 2007 software) considering subjects, sequences, periods and treatments as variation sources. Coefficient of variation (CV) of the ANOVA was calculated according to the equation (1):

$$
C V=100 \sqrt{e^{S^{2}}-1}
$$

With $S^{2}$ being the residual variance of the ANOVA performed on the log-transformed parameters.

A T-Wilcoxon test was used to evaluate the T-R difference for $\mathrm{T}_{\text {MAX' }}$ since a non-normal distribution was assumed. Average bioequivalence between $T$ and $R$, considering all the subjects, was declared if the $90 \%$ confidence intervals $(90 \% \mathrm{Cl})$ for the T/R ratio of the geometric means for each parameter were within the range of $0.80-1.25$, and $\mathrm{T}_{\text {MAX }}$ did not differ significantly.

\section{In vitro/in vivo and pharmacokinetic/pharmacodynamic correlations}

Since only two formulations were assayed, no mathematical correlation will be performed between the in vitro dissolution and in vivo pharmacokinetics of furosemide. Just visual comparisons between percentages dissolved in vitro and percentages of doses recovered in urine from both formulations, in both male and female subjects, will be carried out.

Diuresis and/or electrolyte ER versus furosemide ER will be correlated in order to assessPK/PD relationship in both sexes.

\section{Results}

\section{In vitro studies}

Dissolutions carried out with the USP-2 apparatus revealed that formulation Tremaine at the bottom of the vessels up to its total dissolution, even though it dissolved faster than $R$. Reference disintegrated immediately it was plunged into the dissolution medium ( $\mathrm{pH}$ 4.6). Disintegration in simulated gastric fluid $(\mathrm{pH} 2.2)$ was significantly different between the two formulations, with the formulation T having a higher disintegration time than the formulation $\mathrm{R}(180 \pm 10 \mathrm{vs} .22 \pm 2 \mathrm{sec})$.

Dissolutions performance of the two formulations under all conditions tested are presented in Figure 1. Dissolution of furosemide from $T$ is faster and more complete than from $R$ after $1 \mathrm{~h}$ in the acetate buffer with USP-2 and USP-4 apparatus. In biorelevant conditions with USP-4 apparatus, a negligible dissolution is observed in simulated fasted state gastric conditions for both formulations. Furosemide dissolves slightly faster from $T$ in the first part of the simulated fasted state intestinal conditions, having a complete dissolution at the end of the experiment from both formulations.

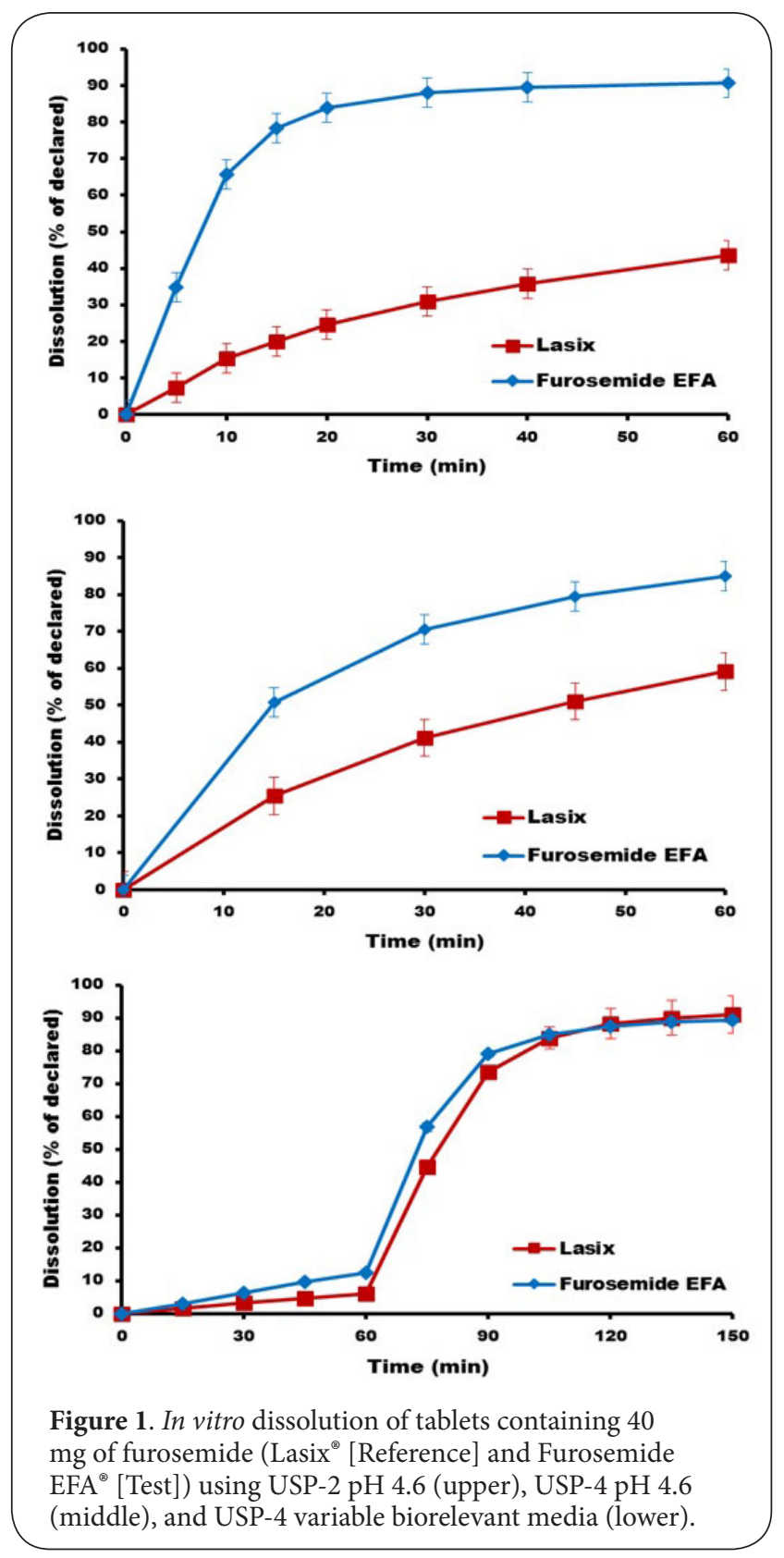


In vivo pharmacokinetic and pharmacodynamic study The mean ER of furosemide throughout time for both formulations in all the subjects, in men, and in women are presented in Figure 2. Table 1 summarizes the mean pharmacokinetic parameters obtained.

Parameters for all electrolytes are summarized in Table 2. Since there was a highly significant linear correlation between ER of urine (diuresis) and ER of chloride (data not shown), this was selected as the PD response of formulations to be presented graphically (Figure 3). A clockwise hysteresis loop was evident in both sexes, being significant in women.

\section{Bioequivalence between formulations}

Table 3 summarizes the ANOVA results and $90 \%$ Cls for $E_{\text {MAX }}$ and $\mathrm{E}_{\mathrm{INF}}$ in the total of individuals and in women. No signifi-
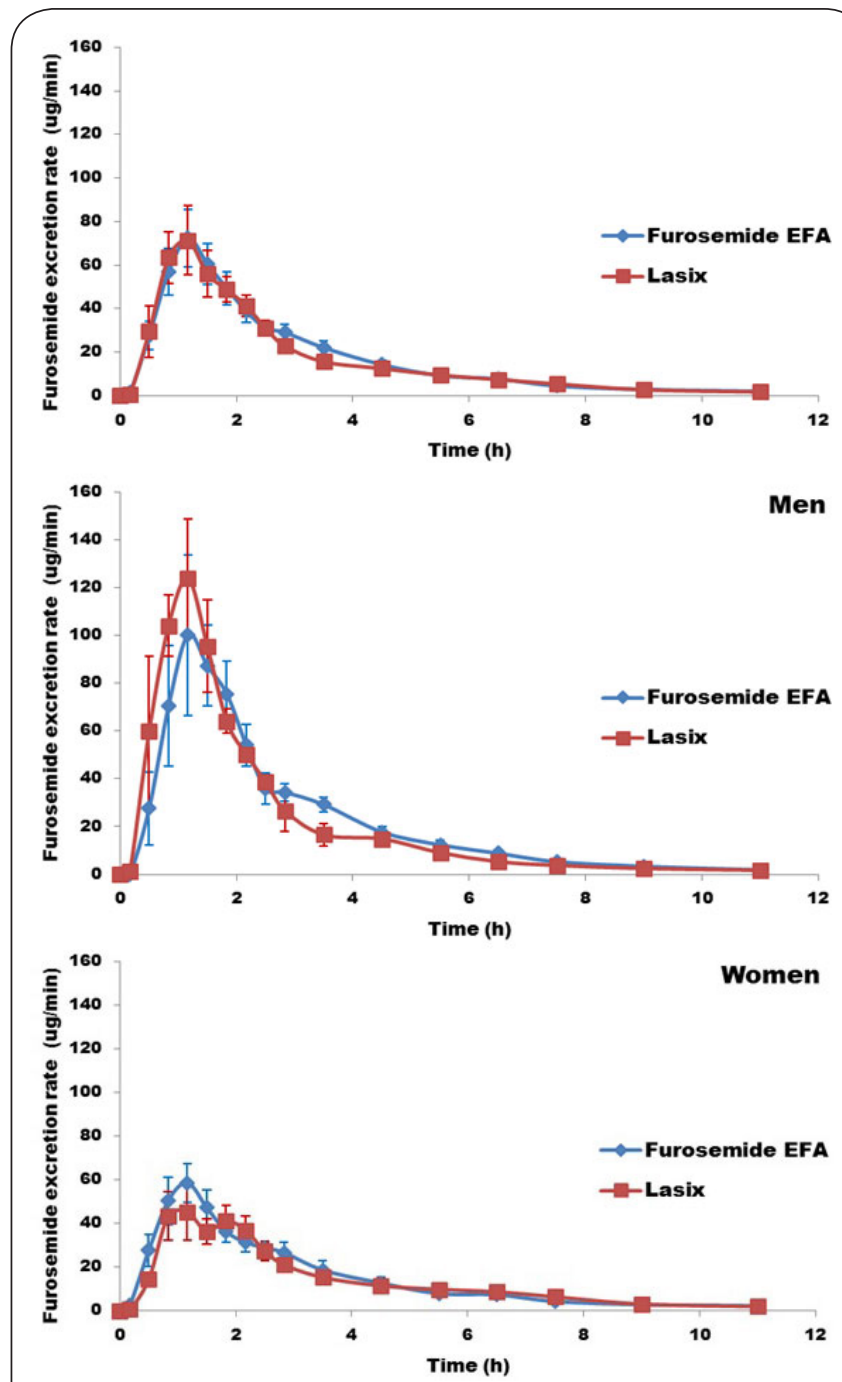

Figure 2. Mean $( \pm$ S.E.) urinary excretion rate of furosemide following a 40-mg oral dose of Lasix ${ }^{\circledast}$ [Reference] and Furosemide $\mathrm{EFA}^{\circledast}$ [Test] administration to 12 healthy Caucasian subjects (upper) [4 men (middle) and 8 women (lower)] under fasting state.
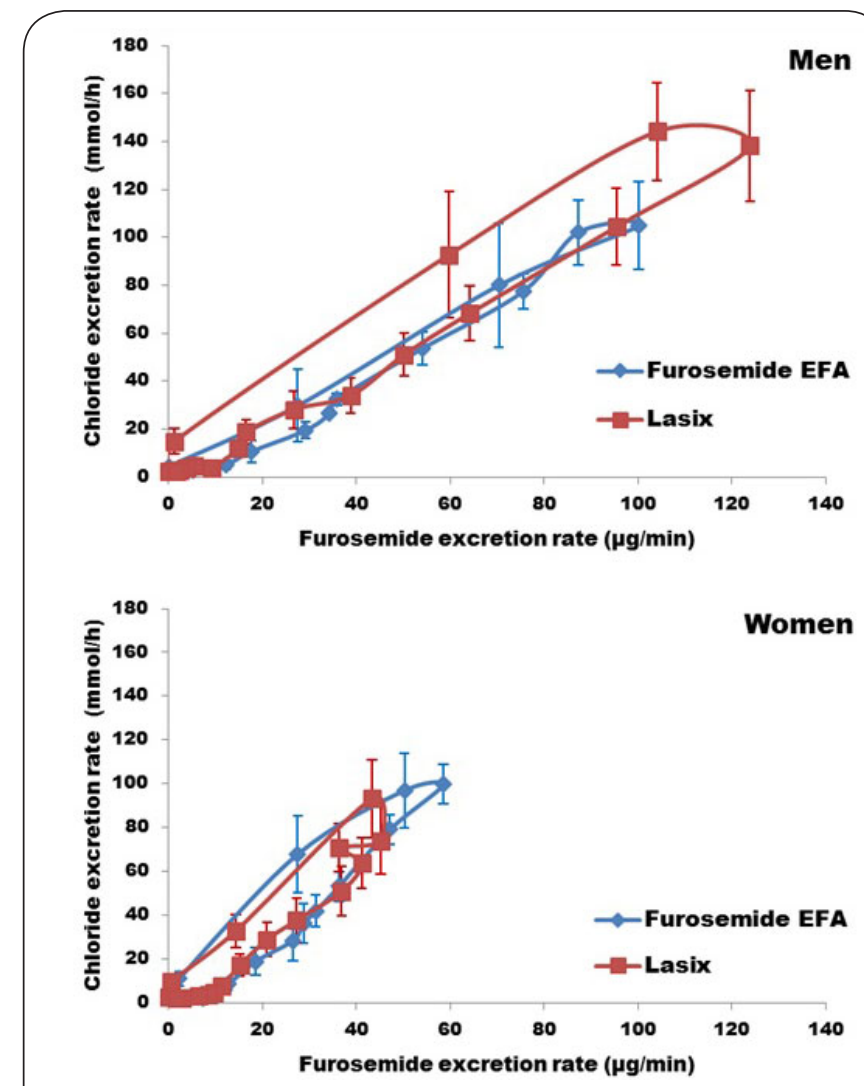

Figure 3. Mean $( \pm$ S.E.) urinary excretion rate of chloride versus mean urinary excretion rate of furosemide after a $40-\mathrm{mg}$ oral administration of Lasix ${ }^{\circledast}$ [Reference] and Furosemide EFA ${ }^{\circledast}$ [Test] to 4 healthy men (upper) or 8 healthy women (lower) under fasting state.

cant difference between formulations was obtained for $\mathrm{T}_{\text {MAX }}$. Considering the sex of individuals, $\mathrm{E}_{0-12^{\prime}} \mathrm{E}_{\mathrm{INF}}$ and $\mathrm{ER}_{\mathrm{MAX}}$ differed significantly $(p<0.01$ in both formulations, mean and SE values in Table 1). Half-life calculated in men (average between formulations $=2.07 \mathrm{~h}$ ) was lower than that in women (average between formulations $=2.24 \mathrm{~h}$ ), but without a statistical significance.

\section{Discussion}

Sex-related differences in the gastrointestinal tract Regarding the bioequivalence between formulations, $T$ could be assessed as bioequivalent with $R$. The extent of absorption in the total subjects (men and women) was similar between both products as revealed by the $90 \% \mathrm{Cl}_{\text {of }} \mathrm{E}_{\mathrm{INF}} \mathrm{T} / \mathrm{R}$ geometric mean ratio being between 0.80 and 1.25 . Similarly, the absorption rate of formulations was assessed as bioequivalent considering the $\mathrm{T} / \mathrm{R}$ geometric mean ratio of $\mathrm{ER}_{\text {MAX }}$ (see Table 3 ) and $T_{\text {MAX }}$ did not differed significantly. Figure 2 (upper panel) supports this average bioequivalence judgment.

However, when only women were considered, bioequivalence could not be assessed because both $\mathrm{E}_{\mathrm{INF}}$ and $\mathrm{ER}_{\mathrm{MAX}} 90 \% \mathrm{Cl}$ of $T / R$ ratios moved to the right and could not be included 
Magallanes et al. Journal of Pharmaceutical Technology \& Drug Research 2016,

http://www.hoajonline.com/journals/pdf/2050-120X-5-2.pdf

Table 1. Arithmetic means [ \pm standard error] of pharmacokinetic parameters obtained in 12 healthy subjects (4 men and 8 women) after a single oral dose of $40 \mathrm{mg}$ of furosemide from Test (T) or Reference $(R)$ formulations.

\begin{tabular}{|c|c|c|c|c|c|c|c|c|c|c|}
\hline & \multicolumn{2}{|l|}{$\mathbf{T}_{\text {MAX }}(\mathbf{h})^{\mathbf{a}}$} & \multicolumn{2}{|c|}{$\mathrm{ER}_{\mathrm{MAX}}(\mu \mathrm{g} / \mathrm{min})$} & \multicolumn{2}{|c|}{$\mathrm{E}_{0-12}(\mathrm{mg})$} & \multicolumn{2}{|c|}{$\mathrm{E}_{\mathrm{INF}}(\mathrm{mg})$} & \multicolumn{2}{|c|}{$T_{1 / 2}(h)$} \\
\hline & $\mathbf{T}$ & $\mathbf{R}$ & $\mathrm{T}$ & $\mathbf{R}$ & $\mathrm{T}$ & $\mathbf{R}$ & $\mathrm{T}$ & $\mathbf{R}$ & $\mathrm{T}$ & $\mathbf{R}$ \\
\hline \multicolumn{11}{|l|}{ Male } \\
\hline & 1.33 & 1.00 & 116 & 133 & 16.0 & 16.1 & 16.3 & 16.7 & 2.02 & 2.12 \\
\hline & [1.17-1.83] & {$[0.5-1.17]$} & [24.5] & [24.2] & {$[2.2]$} & [2.3] & {$[2.2]$} & [2.5] & {$[0.10]$} & [0.09] \\
\hline \multicolumn{11}{|c|}{ Female } \\
\hline & 1.17 & 1.17 & 72.2 & 64.6 & 9.80 & 8.97 & 10.4 & 9.49 & 2.26 & 2.21 \\
\hline & [0.83-2.83] & [0.83-2.17] & {$[6.0]$} & [7.6] & [0.67] & {$[0.92]$} & [0.59] & [0.91] & {$[0.40]$} & [0.36] \\
\hline \multicolumn{11}{|l|}{ Total } \\
\hline & 1.17 & 1.17 & 86.9 & 87.3 & 11.9 & 11.4 & 12.4 & 11.9 & 2.18 & 2.18 \\
\hline & [0.83-2.83] & {$[0.5-2.17]$} & [10.4] & [13.1] & {$[1.2]$} & [1.4] & [1.1] & [1.4] & {$[0.25]$} & [0.23] \\
\hline
\end{tabular}

${ }^{a}$ Median and range is informed for $\mathrm{T}_{\mathrm{MAX}}$

Table 2. Arithmetic means [ \pm standard error] of pharmacodynamic parameters obtained in 12 healthy subjects (4 men and 8 women) after a single oral dose of $40 \mathrm{mg}$ of furosemide from Test (T) or Reference $(\mathrm{R})$ formulations.

\begin{tabular}{|c|c|c|c|c|c|c|}
\hline & \multicolumn{2}{|l|}{$\mathrm{T}_{\text {MAX }}(\mathbf{h})^{\mathrm{a}}$} & \multicolumn{2}{|c|}{$\mathrm{ER}_{\mathrm{MAX}}(\mathrm{mmol} / \mathrm{h})$} & \multicolumn{2}{|l|}{$\mathrm{E}_{0-12}(\mathrm{mmol})$} \\
\hline & $\mathrm{T}$ & $\mathbf{R}$ & $\mathbf{T}$ & $\mathbf{R}$ & $\mathbf{T}$ & $\mathbf{R}$ \\
\hline \multicolumn{7}{|l|}{ Male } \\
\hline Chloride & $1.33[0.83-1.83]$ & $1.00[0.50-1.17]$ & 114 [17] & $157[18]$ & 224 [18] & $278[35]$ \\
\hline Sodium & $1.33[0.83-1.83]$ & $1.00[0.50-1.17]$ & $107[18]$ & 149 [15] & $214[31]$ & $262[30]$ \\
\hline Potassium & $1.50[0.83-1.83]$ & $1.17[0.50-1.50]$ & $12[1.3]$ & 14 [1.9] & $47[2.6]$ & $50[2.8]$ \\
\hline Urine & $1.33[0.83-1.83]$ & $1.00[0.50-1.17]$ & $15.7[2.8]^{\mathrm{b}}$ & $21.0[2.3]^{\mathrm{b}}$ & $2056[251]^{c}$ & $2432[120]^{\mathrm{c}}$ \\
\hline \multicolumn{7}{|l|}{ Female } \\
\hline Chloride & $1.00[0.50-2.50]$ & $0.83[0.83-1.83]$ & $120[9.2]$ & 116 [6.9] & 213 [19] & $198[20]$ \\
\hline Sodium & $1.00[0.50-2.50]$ & $0.83[0.83-1.83]$ & 113 [10] & 110 [7.7] & $199[18]$ & $191[20]$ \\
\hline Potassium & $1.50[0.83-2.50]$ & $1.50[0.83-1.83]$ & $13[0.7]$ & $13[1.0]$ & $44[2.6]$ & $44[3.4]$ \\
\hline Urine & $1.00[0.50-1.50]$ & $0.83[0.83-1.83]$ & $17.0[1.1]^{\mathrm{b}}$ & $17.6[1.2]^{\mathrm{b}}$ & $2227[179]^{\mathrm{c}}$ & $2207[208]^{c}$ \\
\hline \multicolumn{7}{|l|}{ Total } \\
\hline Chloride & $1.17[0.50-2.50]$ & $0.83[0.50-1.83]$ & 118 [7.9] & 130 [9.2] & 216 [15] & 225 [20] \\
\hline Sodium & $1.17[0.50-2.50]$ & $0.83[0.50-1.83]$ & $111[8.6]$ & 123 [8.7] & 204 [15] & 215 [19] \\
\hline Potassium & $1.33[0.83-2.50]$ & $1.17[0.50-1.83]$ & $13[0.6]$ & $13[0.9]$ & 45 [1.9] & $46[2.6]$ \\
\hline Urine & $1.17[0.50-1.83]$ & $0.83[0.05-1.83]$ & $16.6[1.1]^{\mathrm{b}}$ & $18.8[1.2]^{\mathrm{b}}$ & $2170[141]^{\mathrm{c}}$ & $2282[144]^{c}$ \\
\hline
\end{tabular}

Table 3. Pharmacokinetic parameters of furosemide with their respective $90 \%$ confidence interval $(90 \% \mathrm{CI})$ for the $\mathrm{T} / \mathrm{R}$ ratio of means, and ANOVA coefficient of variations $(\mathrm{CV})$, considering all the subjects $(n=12)$ and the group of women $(n=8)$.

\begin{tabular}{lllllll}
\hline Geometric mean & Test & Reference & T/R & IC 90\% & CV (\%) \\
\hline Total & & & & & & \\
\hline $\mathrm{E}_{\mathrm{INF}}(\mathrm{mg})$ & 11.9 & 11.1 & 1.08 & 0.98 & 1.18 & 12.1 \\
$\mathrm{ER}_{\mathrm{MAX}}(\mu \mathrm{g} / \mathrm{min})$ & 81.4 & 77.7 & 1.05 & 0.90 & 1.22 & 21.3 \\
\hline Women & & & & & & \\
\hline $\mathrm{E}_{\mathrm{INF}}(\mathrm{mg})$ & 10.3 & 9.14 & 1.13 & 0.99 & 1.28 & 13.1 \\
$\mathrm{ER}_{\mathrm{MAX}}(\mu \mathrm{g} / \mathrm{min})$ & 70.5 & 61.2 & 1.15 & 1.01 & 1.31 & 13.4 \\
\hline
\end{tabular}

within the bioequivalence interval. Even though no confidence intervals were constructed for male subjects, since only four individuals were enrolled, a faster beginning of drug absorption and a higher maximum excretion rate of furosemide from $\mathrm{R}$, with similar-to-the-T amount of drug excreted (see T-R relative values of $\mathrm{T}_{\text {MAX }} \mathrm{ER}_{\text {MAX }}$ and $\mathrm{E}_{\mathrm{INF}}$ in Table 1) was shown. This is contrary to the performance observed in women, and put in evidence that sexes might discriminate these formulations differently. Figure $\mathbf{2}$ (middle and lower panel) illustrates this statement.

The formulation $\mathrm{R}$ showed a faster in vitro disintegration time. If this is reproduced in vivo, the product would pursue 
along the gastrointestinal tract following the individual physiologic transit. Conversely, $\mathrm{T}$ could have been retained for a longer time in the stomach of male subjects because gastric environment under fasting state is not so aggressive to provoke its rapid disintegration and thereafter its passage to the duodenum, since fluid content and stomach agitation are less intensive [12]. On the other hand, gastric emptying in female subjects is more prolonged than in male, thus, the formulation $T$ would have enough time to disintegrate, making its passage to the duodenum be accomplished at the same time as R. Gastric emptying would only affect the time from which the drug starts its absorption through the intestinal membranes [13]. In the case of men, and for acidic drugs like furosemide, as their higher strength of gastric contraction promotes shorter intervals between each gastric discharge, the faster the formulation disintegrates, the faster its intestinal dissolution starts. Women, with longer intervals of gastric discharge, are unable to differentiate the passage of formulations from the stomach to the intestine even though they could have some differences in their disintegration times.

Therefore, a good correlation between the in vitro dissolution and the in vivo absorption of furosemide would be expected in women. Figure 4 displays similar in vitro/in vivo shapes for the cumulative T-R differences in dissolution and in urinary excretion of furosemide (upper and lower panel, respectively).

The use of sequential change of biorelevant media and physiological relevant flow rates with the flow through cell apparatus led to accurate predictions of the in vivo absorption of furosemide after oral administration of the two formulations (Figure 1). Clearly, not the apparatus, but the condition of the in vitro drug dissolution was the main cause for predicting accurately the in vivo absorption of formulations. The use of a compendial dissolution medium (acetate buffer $\mathrm{pH}$ of 4.6) with the paddle and the flow through cell apparatus was over discriminative. A change in the dissolution conditions passing from gastric to intestinal environment resulted more predictive and realistic for woman subjects instead. Results obtained in men could be reproduced in vitro by simply shortening the gastric residence of the formulation R (Figure 5). In this way, the passage of the R granules to the duodenum, where furosemide dissolution is more effective and its absorption more efficient, was faster (Figure 2, middle panel).

In terms of the amount absorbed in both sexes, it can be seen that a similar amount of furosemide is absorbed from both formulations in man, whereas the fraction of dose absorbed from the two formulations is different in women. It is known that women have a more alkaline intestinal environment than men [14]. This finding explained the sex-related amount of ketoprofen absorbed from extended release formulations and the recirculation rate of its stereoisomers [15]. According to this, it could be hypothesized that women present a shorter absorption window for furosemide (pKa 3.8, [16]) in comparison with men (vertical line in Figures 4 and 5 represent the limit of time above which the absorption would be
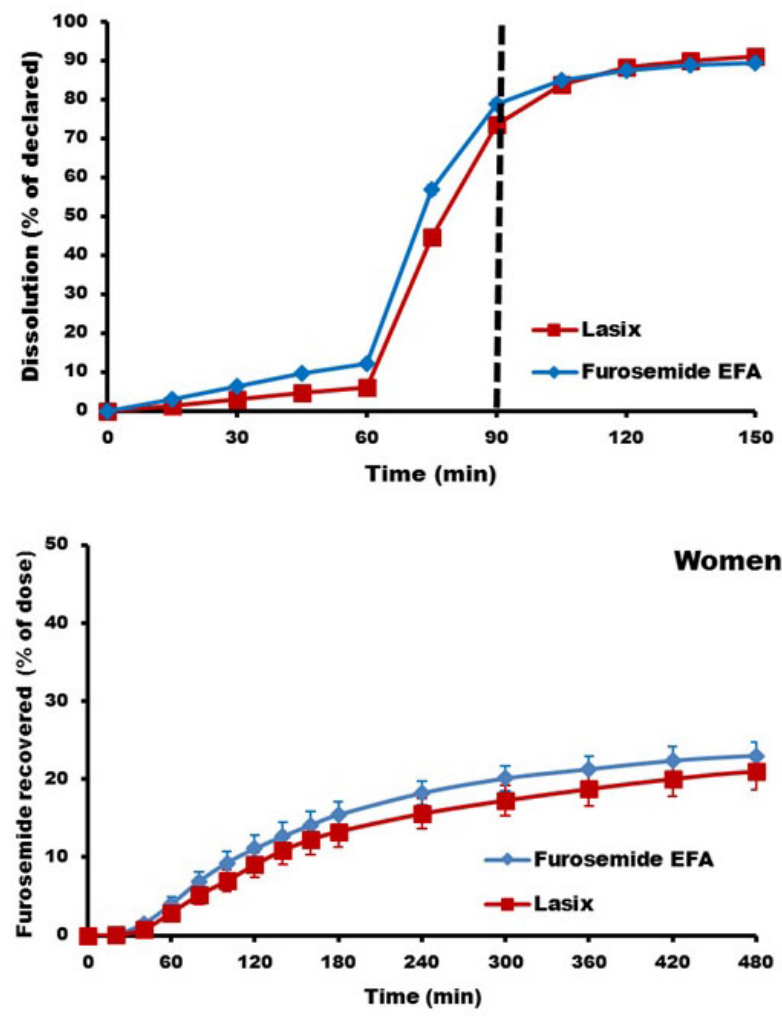

Figure 4. In vitro dissolution of tablets containing $40 \mathrm{mg}$ of furosemide (Lasix ${ }^{\oplus}$ [Reference] and Furosemide EFA $^{\oplus}$ [Test]) using the USP-4 apparatus with variable biorelevant media condition (upper) and in vivo mean $( \pm$ S.E.) cumulative amount of furosemide excreted in urine following $40-\mathrm{mg}$ doses in 8 healthy women (lower). Dashed line indicates the time to stop the dissolution assay in order to find in vitro-in vivo correlation.

negligible, in women and men respectively). For this reason, furosemide could be absorbed to the same extent from both formulations in men. Conversely, since the absorption of the drug drastically diminishes short time after its appearance into the intestinal tract of women, this sex could not allow $R$ (slower dissolution rate) to be absorbed to the same extent as $\mathrm{T}$ (faster dissolution rate).

\section{Sex-related differences in drug absorption and kidney blood perfusion}

Diuretic (saluretic) effect of furosemide is the result of its concentration at the action sites in the ascending limb of the loop of Henle [17]. Arterial blood stream delivers the drug to the kidneys (glomerulus, proximal convoluted tubules and loop of Henle, among others sections of the nephron). One portion of the diffused amount in the renal parenchyma filters through the glomerular membrane. The other part enters the cells of the proximal tubule, of the ascending limb of loop of Henle that contain the saluretic action sites, and the other cells of the nephron. One fraction of this diffused amount returns to 

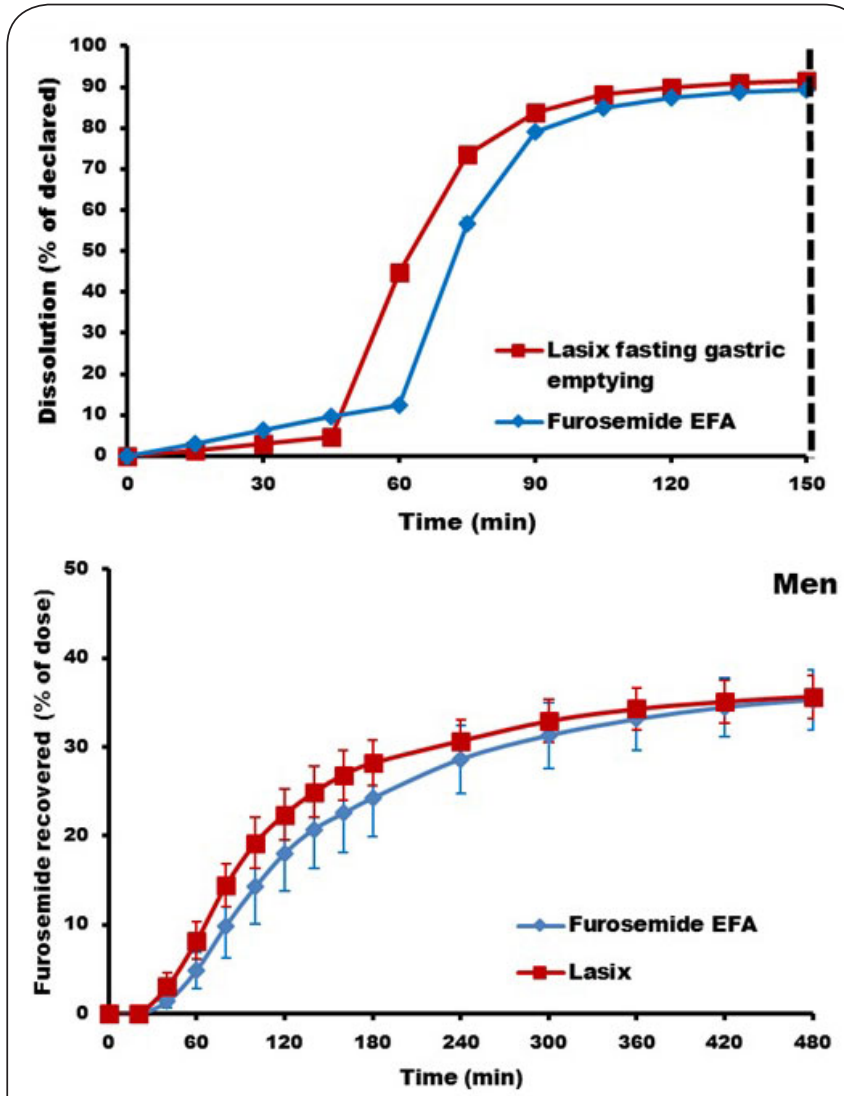

Figure 5. In vitro dissolution of tablets containing $40 \mathrm{mg}$ of furosemide (Lasix ${ }^{\otimes}$ [Reference] and Furosemide EFA ${ }^{\oplus}$ [Test]) using the USP-4 apparatus with variable biorelevant mediacondition and shorter gastric duration for the Reference (upper) and in vivo mean ( \pm S.E.) cumulative amount of furosemide excreted in urine following 40 - $\mathrm{mg}$ doses in 4 healthy men (lower). Dashed line indicates the time to stop the dissolution assay in order to find in vitro-in vivo correlation.

the venous blood stream, while the complementary fraction pursues its renal excretion and metabolism (mainly from the proximal convoluted tubules). Venous blood collects the drug at the concentration it has in the interstitial space of the tissue. In the case of kidneys, this drug concentration is the one it had in the lumen of renal tubules before the current cycle of the circulatory system, mainly from the proximal tubule and the descending limb of the loop of Henle where reabsorption is maximal. In this scenario, and while drug absorption is proceeding, furosemide plasma concentration in the venous blood coming from the kidney would have lower value than in the arterial blood that reaches the organ. There will be a progressive reduction of the arterial-venous concentration difference throughout the absorption process up to the end of drug entrance. After this, the drug will only pursue its disposition throughout the body. Each time the absorption resumes, a new increase in the arterial-venous difference occurs. Theoretical and experimental research dealt with this physiological phenomenon and with its consequence on drug action $[\mathbf{1 8 , 1 9 ] . ~}$

According to this, furosemide would act before it could be excreted, since its arrival at the action sites from the capillaries took lesser time than its arrival at the end of the luminal space of renal tubules from the glomerulus. For this reason, it is not surprising to observe a clockwise hysteresis loop for the relationships between chloride and furosemide ERs (see Figure 3). This resembles what was observed when drug effect, or arterial drug concentration, versus venous drug concentration was graphed for nicotine [19]. Accordingly, furosemide ERs would surrogate their venous plasma concentrations.

This finding was traditionally interpreted in the literature as an acute tolerance to the action of furosemide following single dose administration, mainly when extended release drug formulation or sustained intravenous administration were given $[\mathbf{3}, \mathbf{4}, \mathbf{2 0}-\mathbf{2 3}]$. As it was informed, no hysteresis or a counter-clockwise hysteresis was found after an intravenous bolus dose, revealing, this fact, that there would be a delay between drug concentration in venous blood and drug concentration at the action site (biophase), probably due to the extremely fast drug absorption, and thereafter absorption duration, in comparison with drug diffusion towards the tissue. However, when oral formulations were administered $[3,4,20]$, drug release from the dosage form was slow enough to display such sequential steps in the arterial-biophasevenous concentration. The slower the absorption process is, the wider the clockwise hysteresis loop becomes.

Our results clearly show a difference in the absorption time between sexes. As it can be seen in Figure $\mathbf{3}$ (upper panel), men displayed a more pronounced hysteresis loop after $\mathrm{R}$ than after T administration, even though both PK/PD loops have not reached significance (probably due to the low number of subjects). Once the formulation T passed to the duodenum, its rapid dissolution practically avoided the hysteresis loop. Conversely, repetitive passages of granules from R (tablet fragments) allowed the hysteresis loop to appear. Women slower gastric emptying increased the width of the hysteresis loop significantly $(p<0.01)$, independently of the formulation given (Figure 3 lower panel). Therefore, furosemide absorption kinetics in women was governed by the gastric emptying, and not by the formulation.

As Figure 3 shows women and men do not have the same slope for the PK/PD relationship (see both graphs superimposed in the upper panel of Figure 6). Men had a slower slope. It has been reported [24] that men have a higher percentage of cardiac output destined to the kidneys ( $19 \%$ vs $17 \%$ ). So, a higher percentage of molecules in men (12\%) are driven to the kidneys every blood circulation cycle, and then, their parenchyma would be additionally loaded with furosemide to an extent of $12 \%$ in relation to female subjects [25]. If the furosemide ERs were reduced by a factor of 1/1.12, drug excretion rate of men would be adapted to that of women. In other words, if plasma drug concentrations and kidney/blood concentration ratios were similar between women and men, 

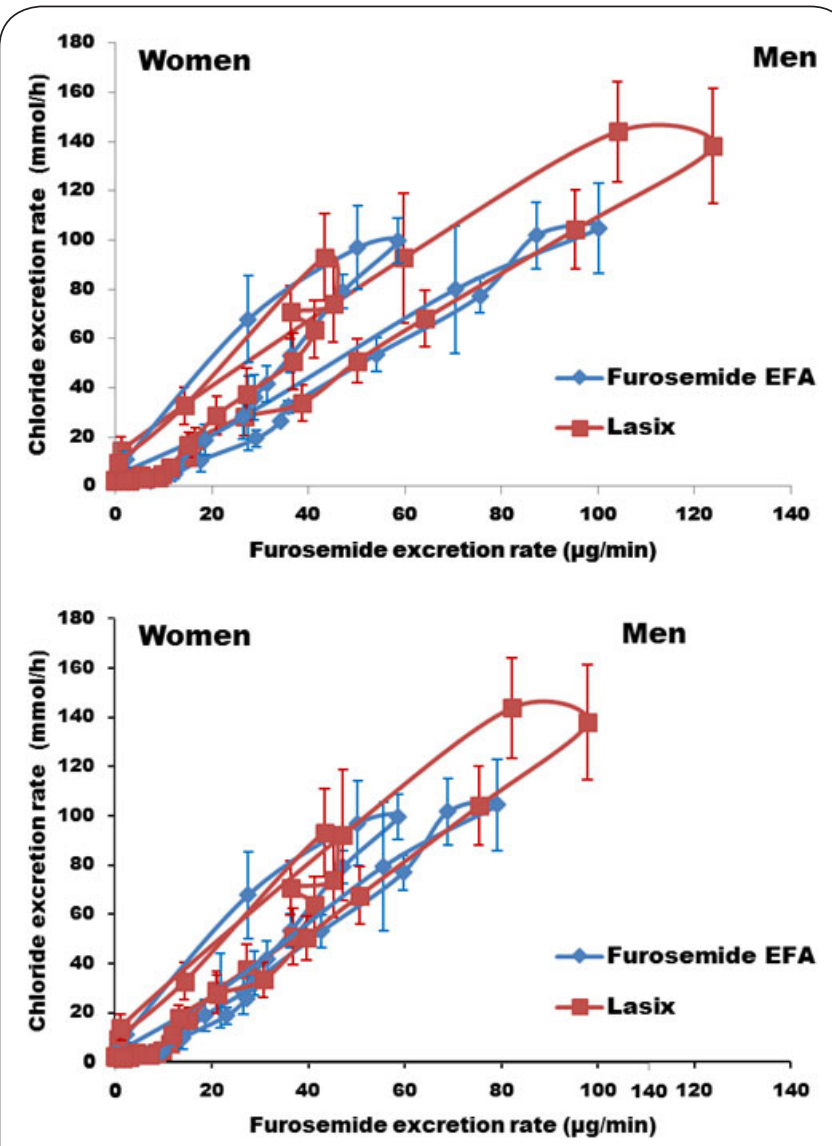

Figure 6. Superimposed graphs shown in Figure 3 (upper) and the effect of straightening just in men the furosemide urinary excretion rate by a factor of 0.80 (lower).

both PK/PD graph should have identical slope provided no difference in their pharmacodynamics would exist. However, even though this transformation was performed sex differences in the PK/PD slope persisted.

Up to now, we assumed that the pharmacodynamics of furosemide did not affect its pharmacokinetics, as if both PK and PD variables were independent. However, it should be born in mind that a higher renal blood flow fraction means not only higher drug concentration at the action site [26-28] but also at the luminal space of tubules, from where urinary excretion of furosemide will take place as a consequence of its own diuretic effect. So, a double contribution of such higher renal cardiac output should be considered to transform the furosemide ERs in men. Then, a straightening of $25 \%$ was applied on the furosemide ER axis (values multiplied by a factor of $0.80[=1 / 1.25])$, and the result can be seen in the lower panel of Figure 6. Now, a good PK/PD correlation was achieved regardless the sex of the individuals. This transformation simply means that men would have a $25 \%$ higher excretion renal clearance than women.

However, it should be kept in mind that the intensity of furosemide action is not linearly related with its concentration, and then, the assumption of a constant factor of 0.80 for the axis straightening should not be entirely appropriate. Renal excretion of furosemide might not be constant, as it is influenced by its diuretic effect. No data about sex differences in the excretion renal clearance $\left(\mathrm{CL}_{\text {excr }}\right)$ of furosemide was published in the literature, but it seems reasonable to admit a higher renal clearance for men taking into account similar findings for other drugs or endogenous substances highly excreted in urine $[\mathbf{2 9}, \mathbf{3 0}]$.

Actual sex-related differences in furosemide oral bioavailability

Previous paragraph leads us to consider whether the urinary excretion of furosemide was reliable enough to assess oral bioavailability difference between sexes. Regarding the values of $\mathrm{E}_{\mathrm{INF}}$ from Table 1, a difference between 16.7 and $9.49 \mathrm{mg}$ for the Reference seems too high in favor of men.

Taking into account that drug plasma concentration (C) and its urinary excretion rate (ER) are related by the equation 2, $E R_{M A X^{\prime}} \mathrm{E}_{0-12^{\prime}}$ and $\mathrm{E}_{\mathrm{INF}}$ data for men, shown in Table 1, should be divided by a factor of 1.25 (man-to-women ratio of excretion renal clearances) in order to be compared with those for women.

$$
E R=C \text { Lexcr } * C \quad \text { (Equation 2) }
$$

These transformed (for men) and non-transformed (for women) values (i.e., $13.4 \mathrm{mg}[=16.7 / 1.25]$ and $9.49 \mathrm{mg}$ for $\mathrm{E}_{\mathrm{INF}}$ respectively) would still maintain sex differences in bioavailability and other clearances apart from the excretion renal one. Assuming that only the bioavailability remained as source of variation, a women-to-men percentage for the absorbed dose would be $75 \%$. So, a supplementary loss of $25 \%$ of the administered dose might be expected for women in relation with men, which could be caused by their higher intestinal $\mathrm{pH}$ and their shorter absorption window.Our estimation is now more in agreement with Waller et al., (1982) [1] and Hammarlund et al., (1984) [2] findings.

\section{Conclusion}

Men and women have dissimilar furosemide oral bioavailability probably due to their differences in the intestinal $\mathrm{pH}$, which in turn produces different absorption windows. The particular intestinal environment that women have was able to differentiate the extent of drug absorption of two immediate-release formulations marketed in Uruguay on the basis of their dissimilar drug dissolution. Conversely, in men drug was absorbed at the same extent because of the longer absorption window available for furosemide. Due to their faster gastric emptying, men were able to differentiate the beginning of drug absorption from both tablets, maybe because of their dissimilar disintegration times during the stay in the stomach. Even though both tablets could have been discriminated by women and men, they are assessed as average bioequivalent considering all the subjects. Minimal differences between formulations were detected both in 
in vivo and in vitro assays, arriving to a good in vivo-in vitro correlation when the USP-4 apparatus under biorelevant conditions was used.

Similarly, the pharmacodynamics of both formulations was equivalent. Once again, different PKPD correlation related with the sex of individuals could be seen. Such sex differences might be explained on the basis of their different renal cardiac output distribution, which influenced their renal excretion as well. Because its diuretic effect, the pharmacodynamics of furosemide interacts with its own pharmacokinetics by increasing its renal excretion. Finally, the excretion rate of chloride is correlated with the excretion rate of furosemide, showing a clockwise hysteresis loop that relates to the rate of drug absorption. In the case of immediate-release dosage forms, the gastric emptying of individuals would control the width of the hysteresis loop more than the formulations themselves, as women and men showed.

\section{Competing interests}

The authors declare that they have no competing interests.

\section{Authors' contributions}

\begin{tabular}{|l|c|c|c|c|c|c|c|c|}
\hline Authors' contributions & LM & PF & MV & NF & MI & ML & VB & AB \\
\hline Research concept and design & $\checkmark$ & $\checkmark$ & $\checkmark$ & $\checkmark$ & -- & -- & -- & -- \\
\hline $\begin{array}{l}\text { Collection and/or assembly of } \\
\text { data }\end{array}$ & $\checkmark$ & -- & -- & -- & $\checkmark$ & $\checkmark$ & $\checkmark$ & -- \\
\hline Data analysis and interpretation & $\checkmark$ & $\checkmark$ & $\checkmark$ & $\checkmark$ & -- & -- & $\checkmark$ & $\checkmark$ \\
\hline Writing the article & -- & $\checkmark$ & $\checkmark$ & $\checkmark$ & -- & -- & -- & -- \\
\hline Critical revision of the article & -- & $\checkmark$ & $\checkmark$ & $\checkmark$ & -- & -- & -- & $\checkmark$ \\
\hline Final approval of article & -- & $\checkmark$ & $\checkmark$ & $\checkmark$ & -- & -- & -- & -- \\
\hline Statistical analysis & $\checkmark$ & -- & -- & -- & $\checkmark$ & -- & -- & -- \\
\hline
\end{tabular}

\section{Acknowledgement}

The first author of this work received a grant from the National Agency of Investigation and Innovation (ANII, POS_NAC_2014_1_102492) Uruguay, and from the Sectorial Commission for Scientific Research (CSIC, University of the Republic, Uruguay).

Publication history

EIC: James A. Radosevich, University of Illinois, USA. Received: 27-Aug-2016 Final Revised: 28-Sep-2016 Accepted: 08-Oct-2016 Published: 19-Oct-2016

\section{References}

1. Waller ES, Hamilton SF, Massarella JW, Sharanevych MA, Smith RV, Yakatan GJ and Doluisio JT. Disposition and absolute bioavailability of furosemide in healthy males. J Pharm Sci. 1982; 71:1105-8. | Article | PubMed

2. Hammarlund MM, Paalzow LK and Odlind B. Pharmacokinetics of furosemide in man after intravenous and oral administration. Application of moment analysis. Eur J Clin Pharmacol. 1984; 26:197-207. | Article | PubMed

3. Alvan G, Paintaud G, Eckernas SA and Grahnen A. Discrepancy between bioavailability as estimated from urinary recovery of frusemide and total diuretic effect. Br J Clin Pharmacol. 1992; 34:47-52. | Article | PubMed Abstract | PubMed FullText

4. Wakelkamp M, Blechert A, Eriksson M, Gjellan K and Graffner C. The influence of frusemide formulation on diuretic effect and efficiency. $\mathrm{Br}$
J Clin Pharmacol. 1999; 48:361-6. | Article | PubMed Abstract | PubMed FullText

5. Prasad VK, Rapaka RS, Knight PW and Cabana BE. Dissolution medium-A critical parameter to identify bioavailability problems of furosemide tablets. Int. J. Pharm. 1982; 11:81-90. I Article

6. McNamara PJ, Foster TS, Digenis GA, Patel RB, Craig WA, Welling PG, Rapaka RS, Prasad VK and Shah VP. Influence of tablet dissolution on furosemide bioavailability: a bioequivalence study. Pharm Res. 1987; 4:150-3. | Article | PubMed

7. Magallanes L, Lorier $\mathrm{M}$, Ibarra $\mathrm{M}$, Vázquez $\mathrm{M}$, Fotaki $\mathrm{N}$ and Fagiolino $\mathrm{P}$. A simple pharmacokinetic model based on mean residence times to predict furosemide exposure after oral doses. Int. J. Pharm. Pharm. Res. 2015; 3:54-65.

8. Jantratid E, Janssen N, Reppas C and Dressman JB. Dissolution media simulating conditions in the proximal human gastrointestinal tract: an update. Pharm Res. 2008; 25:1663-76. | Article | PubMed

9. Fotaki N and Vertzoni M. Biorelevant Dissolution Methods and Their Applications in In Vitro-In Vivo Correlations for Oral Formulations. The Open Drug Delivery Journal. 2010; 4:2-13. I Pdf

10. Sora DI, Udrescu S, Albu F, David V and Medvedovici A. Analytical issues in HPLC/MS/MS simultaneous assay of furosemide, spironolactone and canrenone in human plasma samples. J Pharm Biomed Anal. 2010; 52:734-40. | Article | PubMed

11. Abou-Auda HS, Al-Yamani MJ, Morad AM, Bawazir SA, Khan SZ and AlKhamis KI. High-performance liquid chromatographic determination of furosemide in plasma and urine and its use in bioavailability studies. J C

12. hromatogr B Biomed Sci Appl. 1998; 710:121-8. | Article | PubMed

13. Hall JE. Guyton and Hall Textbook of Medical Physiology. 12th EditionPhiladelphia: Saunders. 2006.

14. Fagiolino P, Vazquez M, Ibarra M, Magallanes L, Guevara N and Fotaki N. Sex- and smoke-related differences in gastrointestinal transit of cyclosporin A microemulsion capsules. Eur J Pharm Sci. 2014; 63:140-6. | Article | PubMed

15. Tuo B, Wen G, Wei J, Liu X, Wang X, Zhang Y, Wu H, Dong X, Chow JY, Vallon $V$ and Dong $H$. Estrogen regulation of duodenal bicarbonate secretion and sex-specific protection of human duodenum. Gastroenterology. 2011; 141:854-63. | Article | PubMed Abstract | PubMed FullText

16. Lorier M, Magallanes L, Ibarra M, Guevara N, Vazquez M and Fagiolino P. Stereoselective Pharmacokinetics of Ketoprofen After Oral Administration of Modified-Release Formulations in Caucasian Healthy Subjects. Eur J Drug Metab Pharmacokinet. 2015. | Article I PubMed

17. Granero GE, Longhi MR, Mora MJ, Junginger HE, Midha KK, Shah VP, Stavchansky S, Dressman JB and Barends DM. Biowaiver monographs for immediate release solid oral dosage forms: furosemide. J Pharm Sci. 2010; 99:2544-56. | Article | PubMed

18. Russell JM. Sodium-potassium-chloride cotransport. Physiol Rev. 2000; 80:211-76. | Article | PubMed

19. Fagiolino $P$, Vazquez $M$ and Eiraldi R. Clearance and bioavailability study through arterio-venous drug concentrations relationship. Eur J Pharm Sci. 2013; 48:825-9. | Article | PubMed

20. Gourlay SG and Benowitz NL. Arteriovenous differences in plasma concentration of nicotine and catecholamines and related cardiovascular effects after smoking, nicotine nasal spray, and intravenous nicotine. Clin Pharmacol Ther. 1997; 62:453-63. | Article | PubMed

21. Klausner EA, Lavy E, Stepensky D, Cserepes E, Barta M, Friedman M and Hoffman A. Furosemide pharmacokinetics and pharmacodynamics following gastroretentive dosage form administration to healthy volunteers. J Clin Pharmacol. 2003; 43:711-20. | Article I PubMed

22. Castaneda-Hernandez G, Verges J, Pichette V, Heroux L, Caille G and du Souich $P$. Input rate as a major determinant of furosemide pharmacodynamics: influence of fluid replacement and hypoalbuminemia. Drug Metab Dispos. 2000; 28:323-8. | Article | PubMed

23. Louizos C, Yanez JA, Forrest ML and Davies NM. Understanding the 
Magallanes et al. Journal of Pharmaceutical Technology \& Drug Research 2016, http://www.hoajonline.com/journals/pdf/2050-120X-5-2.pdf

hysteresis loop conundrum in pharmacokinetic/pharmacodynamic relationships. J Pharm Pharm Sci. 2014; 17:34-91. | Article | PubMed Abstract | PubMed FullText

24. Yagi $N$, Kiuchi T, Satoh $H$, Terashima $Y$, Kenmotsu $H$, Sekikawa $H$ and Takada M. Bioavailability and diuretic effect of furosemide following administration of tablets and retarded capsules to human subjects. Biol Pharm Bull. 1996; 19:616-22. | Article | PubMed

25. Soldin OP, Chung SH and Mattison DR. Sex differences in drug disposition. J Biomed Biotechnol. 2011; 2011:187103. | Article | PubMed Abstract | PubMed FullText

26. Fagiolino $P$, Eiraldi $R$ and Vazquez $M$. The influence of cardiovascular physiology on dose/pharmacokinetic and pharmacokinetic/ pharmacodynamic relationships. Clin Pharmacokinet. 2006; 45:433-48. | Article I PubMed

27. Fagiolino $P$. The influence of cardiac output distribution on the tissue/ plasma drug concentration ratio. Eur J Drug Metab Pharmacokinet. 2002; 27:79-81. | Article | PubMed

28. Fagiolino $P$, Wilson F, Samaniego $E$ and Vazquez M. In vitro approach to study the influence of the cardiac output distribution on drug concentration. Eur J Drug Metab Pharmacokinet. 2003; 28:147-53. | Article | PubMed

29. Fagiolino P. Multiplicative dependence of the first order rate constant and its impact on clinical pharmacokinetics and bioequivalence. Eur J Drug Metab Pharmacokinet. 2004; 29:43-9. | Article | PubMed

30. Rosario MC, Thomson AH, Jodrell DI, Sharp CA and Elliott HL. Population pharmacokinetics of gentamicin in patients with cancer. $\mathrm{Br} J \mathrm{Clin}$ Pharmacol. 1998; 46:229-36. | Article | PubMed Abstract | PubMed FullText

31. Cockcroft DW and Gault MH. Prediction of creatinine clearance from serum creatinine. Nephron. 1976; 16:31-41. | Article | PubMed

\section{Citation:}

Magallanes L, Fagiolino P, Vazquez M, Fotaki N, Ibarra M, Lorier M, Bertola V and Barindelli A. Sex-related in vitro/ in vivo and $\mathrm{PK} / \mathrm{PD}$ correlations after oral single dose furosemide administration. J Pharm Technol Drug Res. 2016; 5:2. http://dx.doi.org/10.7243/2050-120X-5-2 